\title{
Design and Simulation of Jujube Sapling Transplanter*
}

\author{
Wangyuan Zong $^{* *}$, Wei Wang ${ }^{* * *}$, Yonghua Sun, and Hong Zhang \\ School of Mechanical and Electric Engineering, Tarim University Alar, \\ Sinkiang 843300, P.R China \\ Tel.: 0997-4683859 13031270332 \\ zwyzzx@sina.com
}

\begin{abstract}
This paper is aiming at designing a novel jujube transplanter with mechanic arms, which can support the sapling for a while when other operations is going on. It improves uniformity and stability. Pro-E software has been used for the design process, by which transplanting process has been analyzed and simulated.
\end{abstract}

Keywords: Density Jujube Plantation; Sapling Transplanted; Bionic Manipulator; Kinetic Simulation.

\section{Introduction}

As a Chinese special economic fruiter, the cultivated area of jujube trees has increased rapidly in southern Sinkiang in recent 7 years. The cultivated area of the jujube of southern Sinkiang has reached about $300,000 \mathrm{hm}^{2}$ by the end of 2009. The higher and more extensive demand to the corresponding machinery equipment for jujube planting was put forward (Liu Lei et al, 2008). This project developed a kind of jujube transplant machine for the high-density planted model of jujube to adjust to the requirements of jujube industry rapidly development in southern Sinkiang.

\section{Features and Requirement}

The high-density planted model of jujube is the generally adopted model in southern Sinkiang. The high-density planted model is able to realize early results and yield and improve the utilization ratio of land in early and the economic benefit. There are two forms of the high--density planted model: Single-density whose space between trees is $2 \times 3 \mathrm{~m} 、 2 \times 4 \mathrm{~m} 、 1.5 \times 1.0 \mathrm{~m}$; Wide connect narrow row whose space between trees is $1.5 \times 1.5 \times 4 \mathrm{~m}$. The protection for trees furrow should reservation $1.5 \mathrm{~m}$ and the inner

\footnotetext{
Project Funding: Subsidized by Sinkiang Science and Technology Supporting Projects (2009zj19).

** Wuhan in Hubei, Associate Professor, Research Direction: Agricultural Mechanism.

**** Corresponding Author.
} 
diameter should be $1 \mathrm{~m}$ and the both sides of the ridge width is $25 \mathrm{~cm}$. It can not intercropping other crops either in the reservation or on the ridge. The ditch and ridge should be treaded solidly and flatly. Use the way that buried first, extracted second and trampling down third to plant. The roots should be ensuring to be stretch in planted process. The planting depth should be above the root 2 3 cm(Wang Jianxun et al, 2007; Si Yanjiang et al, 2007; Zhang Changjiang et al, 2006).

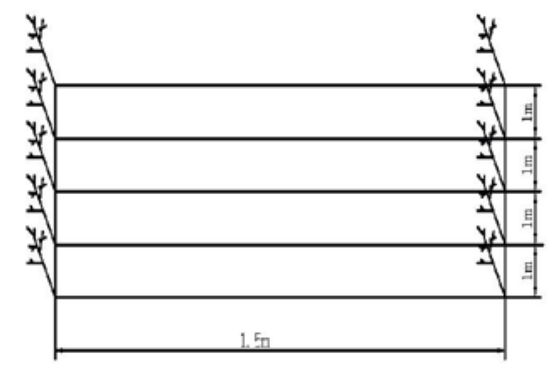

Fig. 1. High-Density Planted Model

Table 1. Planted Technological Requirement of Jujube

\begin{tabular}{|c|c|c|c|c|c|c|}
\hline \multirow{2}{*}{$\begin{array}{l}\text { Technical } \\
\text { Parameter }\end{array}$} & \multirow{2}{*}{$\begin{array}{l}\text { Row } \\
\text { Distance } \\
\text { (m) }\end{array}$} & \multirow{2}{*}{$\begin{array}{l}\text { Planted } \\
\text { Spacing } \\
(\mathrm{m})\end{array}$} & \multicolumn{2}{|c|}{$\begin{array}{l}\text { Planted } \\
\text { Ditch } \\
\text { (m) }\end{array}$} & \multicolumn{2}{|l|}{ Jujube } \\
\hline & & & $\begin{array}{l}\text { Ditch } \\
\text { Width }\end{array}$ & $\begin{array}{l}\text { Ditch } \\
\text { Depth }\end{array}$ & Primary & Secondary \\
\hline $\begin{array}{l}\text { Technological } \\
\text { Requirement }\end{array}$ & 1.5 & 1 & $\begin{array}{c}200 \sim \\
300\end{array}$ & $\begin{array}{c}300 \sim \\
400\end{array}$ & $\begin{array}{l}\text { Sapling Height } \\
\qquad \geq 1 \mathrm{~m} \\
\text { Distance Land } \\
\quad \geq 1 \mathrm{~cm} \\
\text { Root Diameter } \\
\quad \geq 2 \mathrm{~mm} \\
\text { Taproot length } \\
\quad \geq 20 \mathrm{~cm} \\
\text { Quantity of } \\
\text { Lateral Root } \\
\quad \geq 6 \text { strips }\end{array}$ & $\begin{array}{l}\text { Sapling Height } \\
\qquad \geq 0.8 \sim 1 \mathrm{~m} \\
\text { Distance Land } \\
\geq 0.8 \sim 1 \mathrm{~cm} \\
\text { Root Diameter } \\
\quad \geq 2 \mathrm{~mm} \\
\text { Taproot length } \\
\quad \geq 15 \mathrm{~cm} \\
\text { Quantity of } \\
\text { Lateral Root } \\
\quad \geq 6 \text { strips }\end{array}$ \\
\hline
\end{tabular}


The design selects the technical requirements and process characteristics as Fig 1 and Table 1 shows according to the demand of jujube high-density planted model.

\section{Working Principles and Structure Design of Jujube Transplanter}

\subsection{Working Principle}

The work of this mechanical equipment is to perform planting in transplanting process. The furrow opener will complete furrowing in the planting area first before this machine working. Table 1 shows the concrete parameter.

The tractor mounted jujube transplanter, with specially designed mechanic arms to support sapling while soil compacted. The mechanic arms can support the jujube a minute after it planted to maintain the trees orthostatic in covering soil and compacting in working process. The manipulator will move reversely with the whole equipment by the same velocity in working. Therefore, the jujube sapling 's movement is the

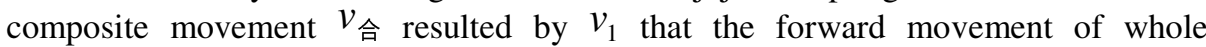
equipment and $v_{2}$ reverse movement of manipulator. That is $v_{\text {sum }}=v_{1}+v_{2}=0$ this makes the process of seedlings planting in the ground remained relatively static. The manipulator will release the sapling and back in situ to prepare the next working after that the roots have been landfill by the coverer and compacting drum. The retractable and trajectory of the manipulator is function by the inner adjusting spring and the track of sapling supported system together and drive by chain conveyor belt.

\subsection{Design of Structure}

The Fig 2 shows the structure principle of the jujube transplanter.

The operator will sit in the seat 2 and put the sapling stored in seeding chamber 7 into the bionic manipulator 10 of the supporting system 3 . Then the sapling will be planted into the planting trench by manipulator 10 transmission with the chain. At this time, the manipulator started to move reversely relative to the whole equipment to maintain the sapling vertical. The quality soil of planting trench will be covered on the roots by the front coverer. After that, the press wheel 5 will compact the soil covered. Afterward, the manipulator releases the sapling under the function of adjusting spring because of the changing of the moving track. Finally, the back coverer 4 mulches the rest of soil to the around of the roots and now complete once work of sapling transplanting. Next step, the manipulator will restore in situ along the track to clip the saplings and wait the recycling operation. There are two plant holder of the sapling supported system and the moving distance is the same as the plant spacing. The adjusted Device of Depth Limited 8 can be use to regulated the depth of the trees planted. Thanks to that the distance between the manipulator and land, as a reason it assures the trees planted have an overall height. The velocity of manipulator relative to the whole machine and the spacing insures the unity of planting spacing and the upright degree of the trees. 


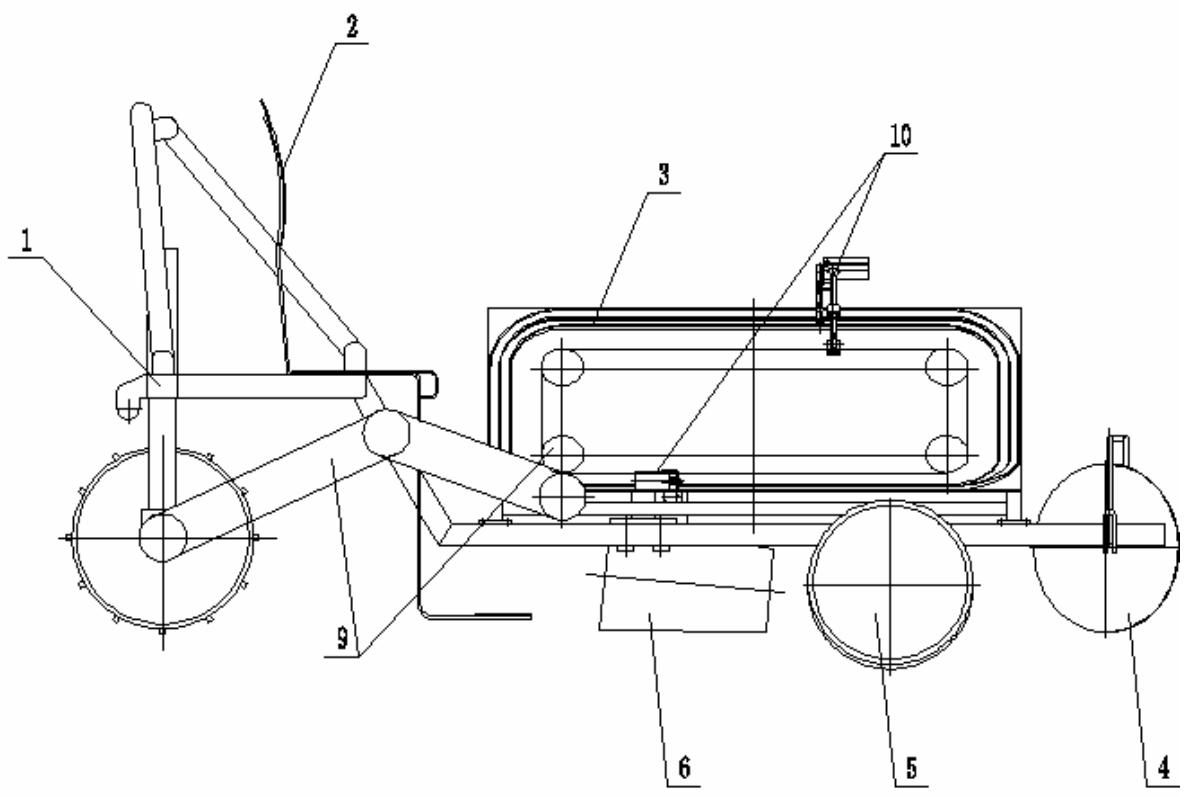

(a)

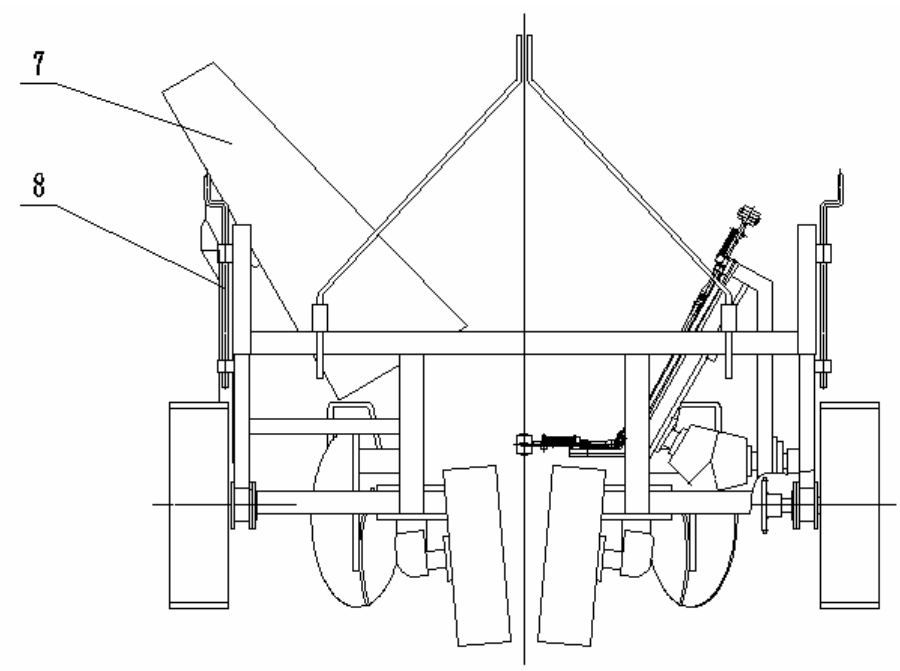

(b)

Fig. 2. Structure Principle of Jujube Transplanter 1Frame 2Seat 3Sapling Supported System 4Back Coverer 5Press Wheel 6Front Coverer 7Seedling Chamber 8Ajusted Device of Depth Limited 9Transmission System 10Bionic manipulator 


\subsection{PROE Simulation Model and Structure Parameter}

Draw three-dimensional model as the Fig 3 shows in the Pro/E software when the structure sizes of the transplanter determined. Do dynamics stability through simulation in the institutional environment of Pro/E for the main components. Shows the simulated reason that there is no interference between each component of the whole machine.

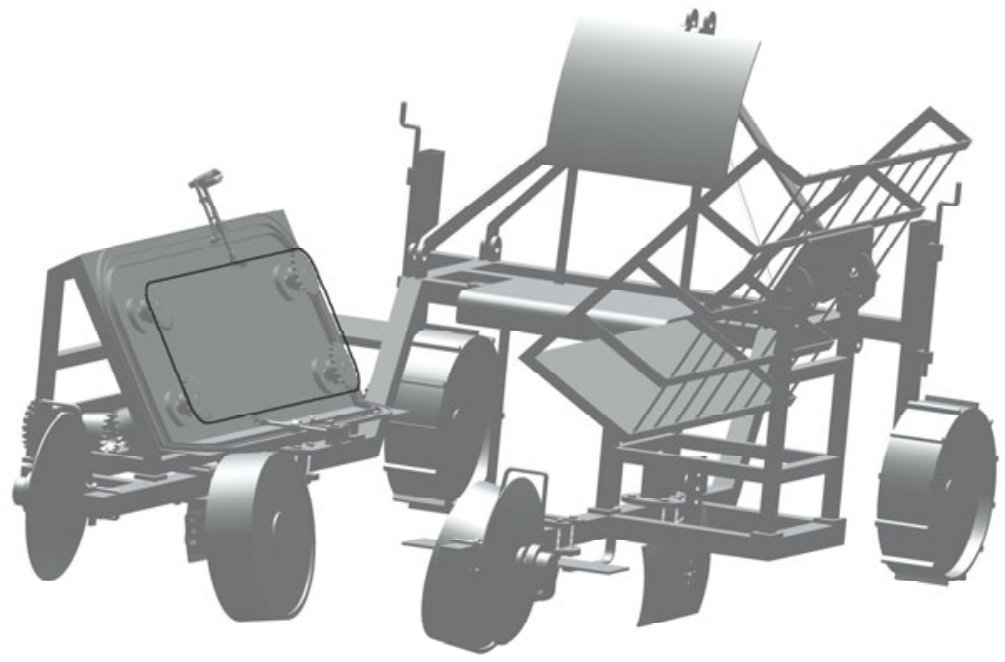

Fig. 3. Pro/E Simulation Model

The main technical performance of transplanting machine is as follows:

The size of whole equipment ( length $\times$ width $\times$ height ): $2017 \mathrm{~mm} \times 1214 \mathrm{~mm} \times 965 \mathrm{~mm}$

Weight: About $210 \mathrm{~kg}$

Mating Power: Variety of wheeled tractors

Efficiency: Related to the velocity of the tractors

Adjustment Range of Spacing: $\geq 800 \mathrm{~mm}$

Plant Spacing: $1.0 \mathrm{~m}$

Planted Depth: $300 \sim 400 \mathrm{~mm}$

\section{Trajectory Analysis of Sapling}

The sapling supported system of the transplater is the most important component in this equipment. It can move along the rail surface transported by the chain and be able to complete the motion of grapping seedling, feeding seedling, supporting seedling and 


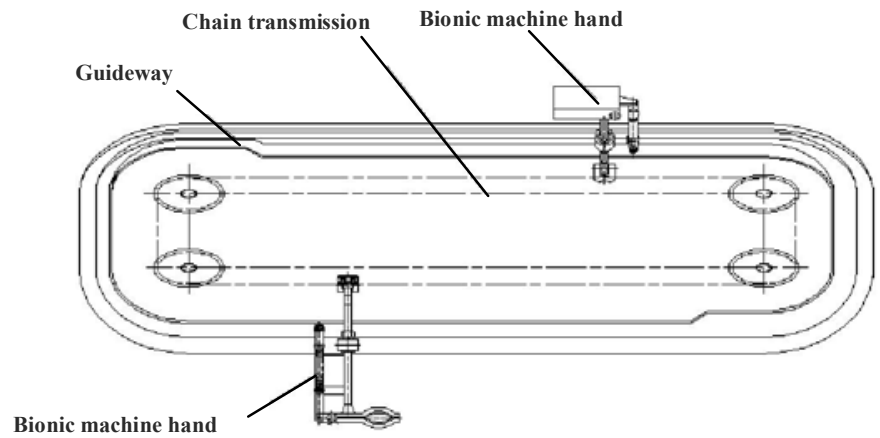

Fig. 4. Structure Chart of Sapling Supported System

design of theory and structure requirements. Therefore, The movement of the sapling is qualitative that has a certain trajectory. In this design, the plant spacing as $s=1$, length of guide in horizontal as L1, length of inclined plane as L2=S-L1, velocity of pull tractor as v. The displacement of direction of coordinate system Fig 5 shows is obtained on the base that the seedling folder position as the point of movement. The guide and the structures of manipulator determine that the angle of manipulator with the ground as $\beta=90^{\circ}-\theta$ before dropping seedling and $\beta=0^{\circ}$ after dropping.
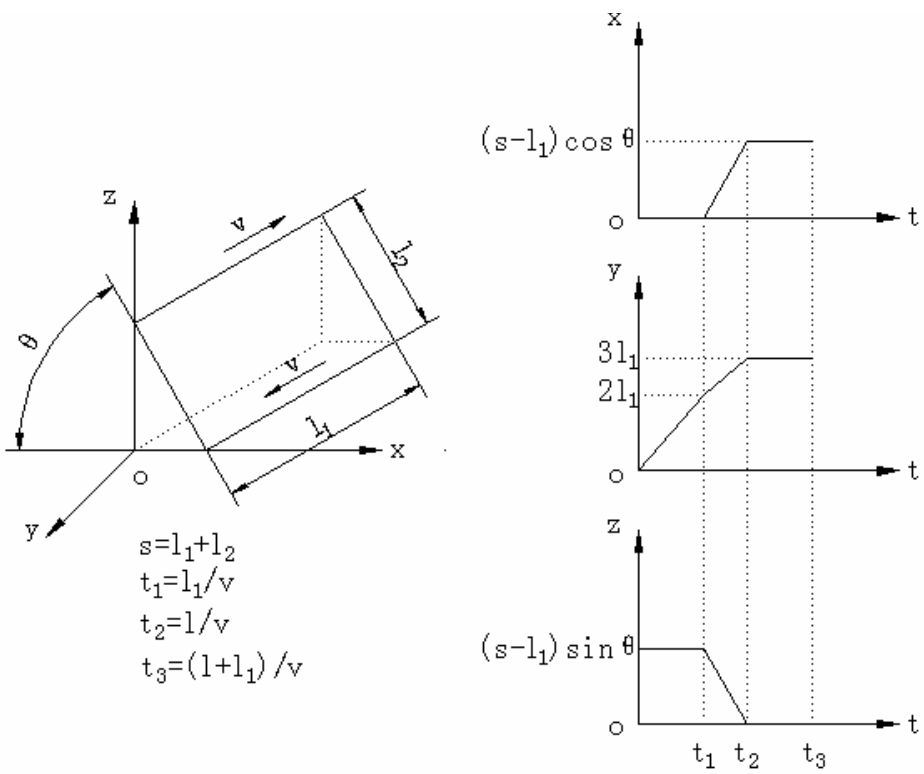

Fig. 5. Movement Analysis Within Coordinates of Sapling 


\section{Conclusions}

The mechanical transplanting can be able to reduce the labor intensity of farmers, increase production and income. The jujube transplanter for the high-density jujube plantation can be capable of reducing the labor intensity and guaranteeing planting perpendicularity and jujube's neat and unity because of the new principle and structures.

(1) According to the technological program, design the sapling supporting system that complete planting automatically and the process of sapling folder-sapling sending — sapling investing — sapling releasing.

(2) Design the transmission to ensure that the movement relationship of the manipulator with the machine so that seedlings planted in the upright;

(3) Design the whole machine to be sure of completing all the operation for casing and compaction preliminary in the stage of sapling supported.

(4) Design the adjusting device of depth limited to regulate the plating depth in a certain range according to the quality of the saplings.

\section{References}

[1] Wang, J., Gao, J.: The Points of Planting and Managing about Jujube in AKESU Area. SHANXI Fruit Tree, 22-23 (January 2007)

[2] Liu, L., Chen, Y., Zhang, Q.: Appliance and Development Survey of Transplant Technology in Sinkiang Corps. Research on Agricultural Machine Popularize, 204-243 (September 2008)

[3] Zhang, C., Xie,C.: Inseminate and Management of shortened orchard, p. 22. Northwest Horticulture (June 2006)

[4] Si, Y., Shong, F.: The Lecture of Jujube Plant Technology in Sinkiang (part four). Country Science, 38-39 (April 2007) 